\title{
The GenMath Machines: Way to Increase Academic Performance of Senior High School Learners
}

\author{
Elymar A. Pascual \\ elymarpascual@rocketmail.com \\ Department of Education, Nagcarlan District, Laguna, Philippines, 4002
}

\begin{abstract}
This study focused on determining the effect of the use of Gen-Math Machines which are manipulatives or teaching tools in one of the core subjects of Senior High School, General Mathematics. The teacher-researcher asked the learners to develop Gen-Math Machines that would elicit the things that they are learning in General Mathematics, and those machines were used in enhancing skills of learners in General Mathematics. One hundred forty-four became the respondents for this study, and they were the grade 11 learners of Talangan Integrated National High School, Nagcarlan, Laguna, Philippines, school year 2017 2018. Data came from the result of a 20-item quiz given after teaching sessions on the topic Exponential and Logarithmic Function - one set of data using teaching process without the aid of Gen-Math Machines while the other set of data came from teaching process with the aid of Gen-Math Machines. For teaching process without the aid of Gen-Math Machine, the learners got a mean of 9.94 and an SD of 4.38 from a 20-item short response quiz. On the other hand, learners got a mean of 14.65 and an SD of 8.87. Learners obtain a higher mean when manipulatives are used during the teaching-learning process. Using t-test for dependent samples, it was found out that teaching process has significant effect to the Mathematical performance of learners. The Gen-Math improved learners' concept and skill in mathematics. Recommendations to mathematics teachers, department head, school heads, family, community and future researchers were left at the end of the study.
\end{abstract}

Keywords: manipulatives; performance; Mathematics

\section{Introduction}

"The greatest impact on learning is the daily lived experiences of students in classrooms, and that is determined much more by how teachers teach than by what they teach.” Dylan William (2011)

With these words of William, we see how the process impacts the learner, more than the knowledge being fed to them. Teachers may have mastery of the topic he is handling but the way to relay those information is another issue that every teacher deal in everyday classroom encounter. Truths and facts in different discipline are intact, or at least, changes not over a generation. Mathematics concepts have been proven for centuries, and still are the concepts being taught today. But the approach, strategy, method and activity should be an ever changing current as the learner changes also in their characteristics.

In this note, teachers should always think of ways in which to effectively communicate knowledge, in a way that they will enjoy, participate, collaborate, and thereby learn with high level of output or performance. 


\subsection{Background of the Study}

In the Eight Habits of Highly Effective $21^{\text {st }}$ Century Teachers, Andrew Churches enumerated the teacher's profile: adaptor, communicator, learner, visionary, leader, model, collaborator and risk taker. As a collaborator, educators must be able to leverage tools that would enhance and captivate learners.

The Senior High School of Talangan Integrated National High School has eight core subjects for the first semester of school year 2017-2018. They are Oral Communication, $21^{\text {st }}$ Century Literature, Komunikasyon at Pananaliksik, General Mathematics, Earth and Life Science, and Physical Education and Health. The enrolees for grade 11 this school year adds up to 144: 38 for General Academic Strand and a combined 106 (coming from three sections, TVL 11A, TVL 11B and TVL 11C) for Technology, Vocational and Livelihood (TVL). The researcher is their teacher in General Mathematics.

The teacher would like to investigate the possible significant effect of the use of manipulatives in teaching Mathematics. So he asked the learners to develop a Gen-Math machine - a tool that would teach learners General Mathematics' concept and skills. Each of the four sections was divided into five groups, thereby creating 20 Gen-Math machines. The machines created have different features - a dart board that would elicit questions in Gen. Math for learners to answer, a drop ball, a graphing board, a robot that contains question and answers in his belly, a draw lots machine, a rolling ball maze mechanism, a color game board that contains questions in Gen. Math, a spinning board, and a drop ball that has several outcomes for different questions to answer. (See Appendix)

The teacher had a series of classroom sessions on the topic Exponential and Logarithmic Function for a week without the aid of Gen-Math machines, a 20-item quiz was given and the result is recorded. The following week, series of classroom sessions with the same topic for a week was held, a 20-item quiz was given and the result was again recorded. The whole result of this investigation is recorded in this study.

\subsection{Theoretical Framework}

The Cone of Learning by Edgar Dale shows the two bottom parts of the pyramid : simulating the real experience and doing the real thing.

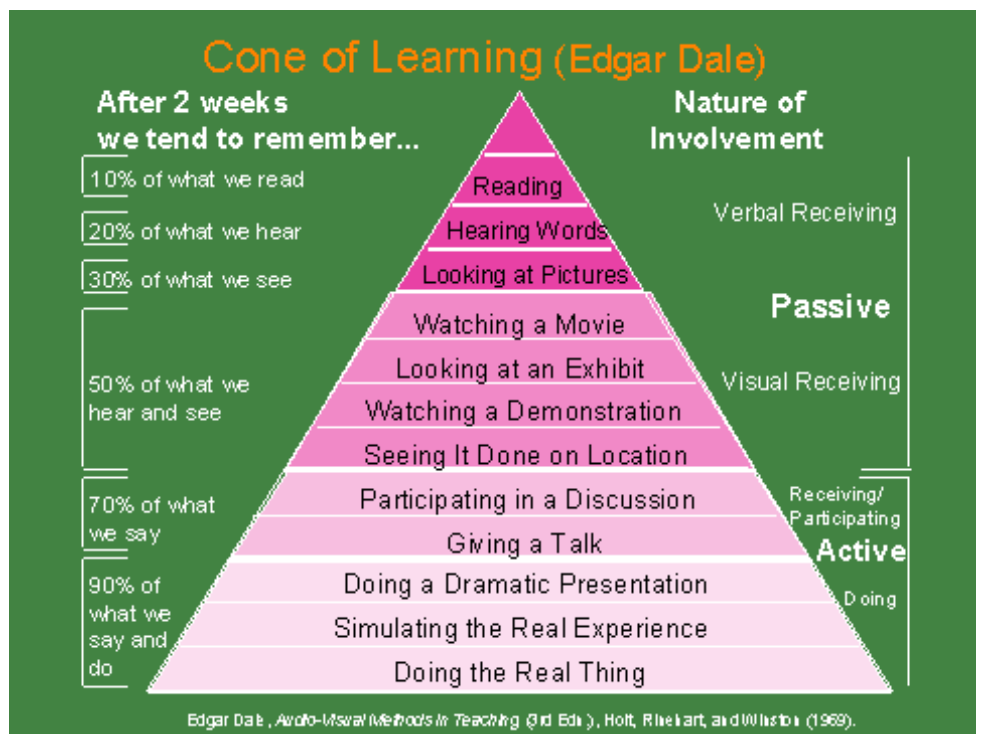

Fig. 1. Edgar Dale's cone of learning 
Students are at the highest peak of learning when they actively participate. By simulating the real experience and doing the real thing, they are able to connect the abstract into concrete, the principles into application, and the skill into practice.

\subsection{Conceptual Framework}

The figure shows the conceptual model of this study. The figure below shows the conceptual framework for this study.

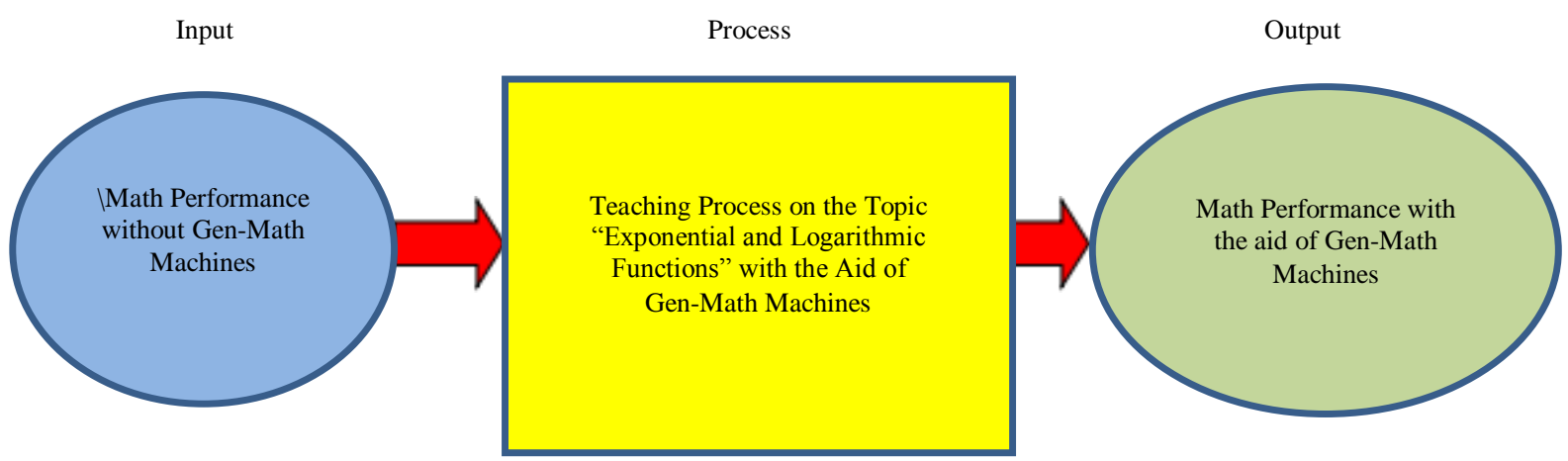

Fig. 2. The conceptual framework of the study

The input is consists of Math performance without the aid of Gen-Math Machines. For the process, the teacher made use of learners-made Gen-Math machines as manipulatives during the teaching-learning process. And for the output, the teacher gave a 20-item quiz and recorded their performance.

\subsection{Statement of the Problem}

This study will aim to determine if the use of Gen-Math Machine will increase the academic performance of Senior High School learners in Talangan Integrated National High School in General Mathematics.

Specifically, it seeks to answer the following question.

1.) What is the mean level of academic performance of Senior High School learners of Talangan Integrated National High School in General Mathematics without the aid of Gen-Math Machines?

2.) What is the mean level of academic performance of Senior High School learners of Talangan Integrated National High School in General Mathematics with the aid of Gen-Math Machines?

3.) Is there a significant difference between the academic performance of learners with and without the aid of Gen-Math Machine?

\subsection{Scope and limitations}

This study was conducted in the first quarter of the school year 2017-2018, that is, from June to August of 2017 using the learners of General Mathematics which is one of the core subjects in Senior High School curriculum. Four sections of Grade 11 became the subjects of this research. The result of this study does not encompass other math subjects for either senior high school or junior high school. Nevertheless, this can be replicated for the purpose of knowing if the result would be the same for other math subjects and other grade level. 


\section{Review of Related Literature}

Which among school and home environments affect academic performance? A study made by Visser (2015) revealed that both school and home environments play significant role in learners' mathematics performance. Some learners rely on working memory in dealing with mathematics. They just memorize facts, steps and concepts. Consequently, the performance of individuals who rely most heavily on working memory for successful execution is most likely to decline when the pressure is on. (Beilock, 2008). The study made by Crane (2010) indicate that public schools' bureaucratic regulations for teacher education, curriculum and instruction helps instead of hinder learners' performance in Mathematics. Moirao (2010) highlighted four types of learners in Mathematics: mastery learners, understanding learners, self-expressive learners and interpersonal learners. This is the reason why teachers in Mathematics need to be creative and flexible in dealing with everyday lessons. Visual representations is indispensable because it is a complex process that attempts to make abstract concepts tangible, difficult ideas understandable, and multifaceted problems solvable. (Steedly, 2008). Many educators support the use of visual representations or manipulatives. Burns (1992) advised teachers to allow time for students to be creative, and that includes making their own model of what they are learning in Math. Pehkonen (1997) encouraged teachers to give opportunities to students to work on problems that require resourcefulness and creativity. Colgan (2014) underlined the solution to learners' misbehavior, "Many students find math boring and disengaging; use games, apps, TV programs, and books to make math fun." Rittle-Johnson (2016) on the other hand promotes using physical movements in the classroom. Protheroe (2007) found out that middle ages are already experiencing important crossroads in their mathematical education, "forming conclusions about their mathematical abilities, interest, and motivation that will influence how they approach mathematics in later years." And so, the senior high school stage is a shock absorber of what they have already develop in their minds in former years, in which, teachers need to be creative and flexible in handling or in giving solution to learners' difficulties.

\section{Research Design}

This study utilizes an experimental design in doing research. According to Blay (2013), this design is used when the researcher would like to investigate on the cause and effect relationship, and this paper has that purpose - to find out the effect of using Gen-Math Machines to the academic performance of SHS learners of TINHS.

\subsection{Population}

The population for this study is the grade 11 learners of Talangan Integrated National High School, school year 2017-2018. The sections and frequency is presented in the table below.

Table 1. Participants of the study

\begin{tabular}{|c|c|}
\hline Sections & Number of Learners \\
\hline GAS 11 Vibrant & 28 \\
\hline TVL 11A & 40 \\
\hline TVL 11B & 38 \\
\hline TVL 11C & 38 \\
\hline Total & $\mathbf{1 4 4}$ \\
\hline
\end{tabular}


3.2. Data Gathering Procedure

Data and results were gathered and analyzed using the following steps undertaken by the teacherresearcher:

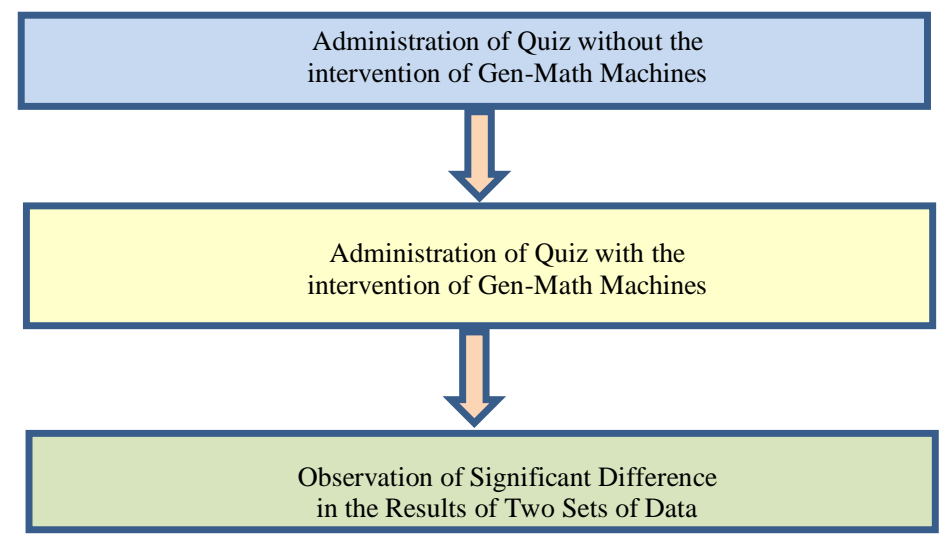

Fig. 3. Steps undertaken in gathering data for the study

Mean and standard deviation were used to analyze the data gathered from series of quizzes with and without the intervention of Gen-Math Machines. For the significant difference between the two arrays of data, t-test for independent samples was used.

\section{Presentation, Interpretation and Analysis of Data}

The table shows the result of the of a 20 -item quiz given to grade 11 learners of Talangan Integrated National High School.

Table 2. Result of t-test for dependent samples

\begin{tabular}{|c|c|c|c|c|c|c|c|}
\hline $\begin{array}{c}\text { Teaching } \\
\text { Process }\end{array}$ & n & Mean & SD & T-critical & T-computed & P-value & Decision \\
\hline $\begin{array}{c}\text { Without Gen- } \\
\text { Math Machines }\end{array}$ & 144 & 9.94 & 4.38 & & 1.97 & -5.71 & 0.00 \\
\cline { 1 - 4 } $\begin{array}{c}\text { With Gen-Math } \\
\text { Machines }\end{array}$ & 144 & 14.65 & 8.87 & Significant \\
\hline
\end{tabular}

alpha $=0.05$

The two teaching processes being compared are classroom sessions without the aid of Gen-Math Machine and classroom sessions with the aid of Gen-Math Machine. Without the aid of Gen-Math Machine, the learners got a mean of 9.94 and an SD of 4.38 out of a 20-item quiz on the topic Exponential and Logarithmic Function. On the other hand, using Gen-Math Machine, the learners' mean is 14.65 and SD is 8.87. This shows that learners did better in the teaching-learning process when the Gen-Math Machine is used to learn concepts and skill in Mathematics. Using t-test for dependent samples, the T-critical is 1.97 while the T-computed is -5.71. Since the absolute value of the T-computed is greater than the T-critical, it can be said that there is a significant difference between the two means. The P-value 0.00 which is lower than the alpha 0.05 supports the claim that there is a significant difference between the scores in quiz without Gen-Math Machine and with Gen-Machine, thus, the implication that the teaching process affects the Mathematical 
performance of grade 11 learners. When Gen-Math Machine is used alongside teaching and learning, higher Mathematical performance is exhibited by the learners compare with the teaching process without the aid of Gen-Math Machine. The result of this study is supports Burns (1992) who advised teachers to allow time for students to be creative, and that includes making their own model of what they are learning in Math. Also, the outcome of this paper is the same with Pehkonen (1997) who promotes encouragement for teachers to give opportunities to students to work on problems that require resourcefulness and creativity.

\section{Recommendation and Reflection}

\subsection{Recommendation}

Based from the result of this study, the researcher recommends the following to targeted person or group of people:

a. Math teachers should continue to develop teaching tools that would enhance teaching and learning process and would motivate learners to achieve more.

b. Department heads may initiate projects, seminar and workshops that would encourage teachers to explore or even to take risk in developing new strategies that would cater to $21^{\text {st }}$ century learners.

c. Schools heads may strive develop the culture of excellence by giving credit and recognition to teachers who are always on tract of developing and utilizing instructional tools which are not traditional but is inventive and creative.

d. Parents and community can go along with the school is aiming by participating and communicating with the school with regards to what they can do or how they can help in the promotion of new instructional tools which in turn would benefit their children and the citizen of the community.

e. Future researchers can further investigate on the effect of manipulative and other instructional tools which are products of teachers' ingenuity in promoting excellence in teaching.

\subsection{Reflection}

Teaching and learning is a life long journey. Not everything is already invented or discovered in the field of teaching. Just like human language, it is alive and continues to develop as generations come and go. The $21^{\text {st }}$ century learners require $21^{\text {st }}$ century teachers, otherwise, teaching and learning would just become a commercial business that would suffice material and financial needs of teachers. Teaching and learning shouldn't be a mismatch in a sense that teachers should plan decisively and systematically every valuable meeting with the learners.

The researcher learned that teachers should not settle for mediocrity. Learning can happen by chance, but high achievement is a result of careful planning and delivery. A teacher should continue to discover and updates himself, explore not only his own world but more importantly the world of the learners. He needs to reach out and not just sit down. He is step into their shoes and not be left behind by traditions. Sore high dear teachers and readers! Continue to uplift the education standard. Touch the future by teaching learners in a way that they will challenge them to make their world a better place.

\section{References}

Beilock, S. L. (2008). Current directions in psychological Science - Math performance in stressful situations. The University of Chicago. Association for Psychological Science.

Blay, B. E. (2013). Elementary statistics. Anvil Publishing, Inc. 
Burns, M. (1992). About teaching mathematics: A K-12 resource. Cuisenaire Company of America.

Colgan, L. (2014). Making math children will love: Building positive mathitudes to improve student achievement in mathematics. What Works? Research into Practice Research Monograph. 56. Student. Achievement Division, Ontario Ministry of Education.

Crane, C. C. (2010). Mathematics performance in public and Catholic elementary schools: Explaining the disparity. [Dissertation submitted in partial fulfillment of the requirements for the degree of Doctor of Philosophy in Elementary Education in the Graduate College of the University of Illinois at Urbana-Champaign].. Urbana, Illinois

Moirao, D. R. and Warrick, P. L. (March 8, 2010). Math tools and strategies for differentiating instruction and increasing student engagement. ASCD 2010 Annual Conference. San Antonio, TX.

Pehkonen, E. (1997). The state-of-art in mathematical creativity. ZDM, 29(3), 63-67.

Protheroe, N. (2007). What does good Math instruction look like?" Principal 7(1), pp. 51 - 54.

Rittle-Johnson, B., \& Jordan, N. (2016). Synthesis of IES-funded research on mathematics: 2002-2013. National Center for Special Education Research

Steedly, K., Dragoo, K., Arafeh, S. and Luke, S. D. (2008). Effective Mathematics instruction. Evidence for Education. Volume III Issue I.

Visser, M., Juan, A. and Feza, N. (February 2015). Home and school resources as predictors of mathematics performance in South Africa. South African Journal of Education, Volume 35, Number 1.

William, D. (2011). Embedded Formative Assessment. Bloomington: Solution Tree Press. 